\title{
TECHNOLOGY ENHANCED LEARNING ASSISTED BY FREE AND OPEN SOURCE SOFTWARE
}

\author{
Vikas Rao Naidu ${ }^{1 \star}$, Baldev Singh ${ }^{2}$, Raya Ali Al Harrasi ${ }^{3}$, Haleema Hassan Al Balushi ${ }^{4}$ \\ ${ }^{1}$ Mr., Middle East College, Oman, vikasrn@gmail.com \\ ${ }^{2}$ Dr., Vivekananda Institute of Technology, India, baldev.vit@gmail.com \\ ${ }^{3}$ Ms., Middle East College, Oman, r92oman@gmail.com \\ ${ }^{4} \mathrm{Ms}$., Middle East College, Oman, haleema.h56@gmail.com \\ ${ }^{*}$ Corresponding author
}

\begin{abstract}
The education system of the present day has undergone a great revolution, with the enhancement of education technology. Especially in the higher education sector, IT is playing a vital role in the advancement of teaching and learning practices. Most of the educational organizations have already adopted smart learning environment by upgrading their infrastructure and with proper capacity building among staff members. But in the education sector, sustainability of technology is always being a challenge. To develop learning materials, many institutions have already started using free and open source software (FOSS) tools. FOSS gives freedom to the developer with the provision of various customization options as per the requirements of the class or subject. Moreover, in the longer run, free and open source software could be considered as the best option in education for e-learning implementation, for sustainability. There are many tools which are available for e-learning resource development. Some of them are available online and some are available as an installer for the various platform. In order to adapt ICT in education, especially in non-IT specialization, the faculty members need the training to learn and implement these tools in their classes. But there are many tools, which are specially designed for educators with basic knowledge of computers. Educators can plan their sessions, based on content, duration as well as the level of the subject and the students. This research paper will highlight various aspects of the implementation of FOSS, in education by using such easy-to-implement tools and techniques. This would provide general guidelines for the development of various e-learning solutions for technology-enhanced teaching and learning practices in higher education.
\end{abstract}

Keywords: Free and open source software, E-learning, Sustainability in education, Technology-enhanced learning, Enhanced teaching and learning practices, Interactive educational tools, Multimedia in education.

\section{INTRODUCTION}

Higher education sector is continuously adapting the latest teaching and learning strategies, to provide quality education with enhanced student learning experience. Education technology is taking up a new shape in present days with the involvement of several e-learning tools. Proprietary software tools are using 
in many practical classes. But when it comes to asset building with respect to learning resources, then it is good if the organization think about adopting free and open source (FOSS) platform. One of the major reason is the option for customization of these resources to any level. Customization of e-learning content is needed as per the level of the module and its content. In many educational organizations, Moodle is customized and implemented as the key Learning Management System (LMS). Although Moodle has many inbuilt options for assessing students learning, such as Quiz, forum, etc., still additional tools could help in building learning resources. E-learning resources are not limited to e-books, rather it involves other multimedia content such as audio, video, graphics, animation, and interactive tutorials.

"The potential of e-learning expands when the developer embraces the widest possible range of individual learning styles, preferences, and abilities", (Pankaja 2013).

\section{FEATURES REQUIRED FOR E-LEARNING SOLUTION DESIGN}

Open source software (OSS) is expanding its root in the education sector. There are several advantages of using OSS to develop e-learning resources.

\subsection{Customisation}

The main advantage of implementing open source software is that it allows any level of customization as per the requirement. For example, LMS Moodle can be customized as per the requirements of the educational institutions. The developer can define the workflow as per the guidelines provided by the institution. Faculty members can further customize their course pages as per their requirements and create assessments of various types.

\subsection{Cost effectiveness}

Another reason for implementing OSS in higher education is financial implications. As these tools are totally free of cost, there is almost nil budget involved in licensing. Moreover, upgrades to the old version to new version are also possible without any financial implications. This feature is very important from the point of view of sustainability in higher education sector. Moreover, it is also beneficial for the students since procurement of these tools are very easy and they can be distributed among all students without any issue related to copyright or licensing.

\subsection{Cross platform compatibility}

Most of these software tools are compatible with all the available platforms, from PC, Mac to Mobile. This allows expansion of usage of e-learning solution over a wide variety of devices. Students can use these resources even on their handheld devices. Cross platform compatibility provides freedom of implementation of these resources. Hence scope of usage increases when we implement such tools which can be run simultaneously on different devices.

\subsection{Replacement}

In case the end user finds a better option than the existing one, they can directly discard the previous tool and go for new ones because they are not going to lose any money since both are free of cost. On the other hand, proprietary tools becomes difficult to discard, since huge amount of money is involved in procuring it especially for an institution, where bulk-licensing option is generally opted. Since open source software are free of cost, one can just discard them if better option is available.

\subsection{Availability}

Most of these tools are available with $24 \times 7$ online support from various developers. Mostly such supports are available on open forums where one can post a query and receive n-number of possible solutions or responses.

\subsection{Scalability}

Due to the flexible environment for development, the e-learning materials developed using FOSS can be scaled to any extent in future without any complications. Based on the feedback and review by the students, faculty can later expand the features in the learning resources.

The above features facilitate the implementation of OSS for e-learning solution development in higher education institutions. In some colleges and universities, students are being encouraged to develop learning resources as a part of assessments and projects. These foster entrepreneurship skills among the young generation towards the development of new and enhanced solutions. 


\section{METHODOLOGY}

The methodology suggested for implementation of FOSS for learning resource development is an iterative process, consisting of six major phases, as shown in the Fig.1.

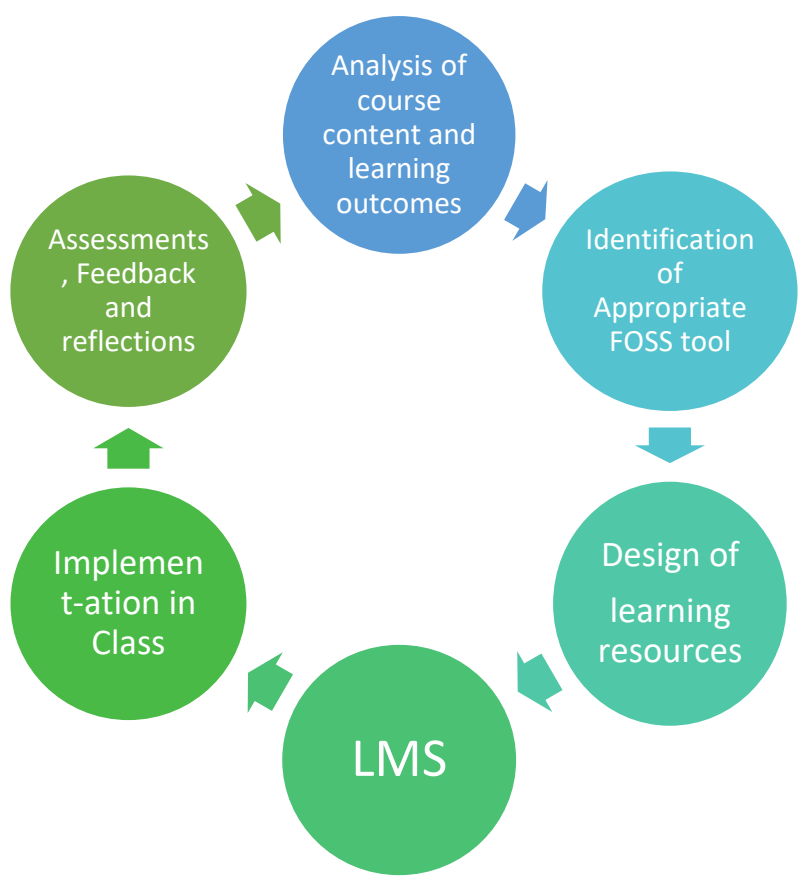

Figure 1. Proposed model

\subsection{Analysis of course content and learning outcomes}

In this stage, various course content and their learning outcomes are analyzed for identifying the topics which need the assistance of learning resources to enable enhanced learning mechanism in classes. As per the requirement, the developer needs to identify which type of solution needs to be designed for it, e-book, or video or animation etc.

\subsection{Identification of appropriate FOSS tool as teaching and learning resources}

As per the requirement identified above, the developer needs to identify appropriate FOSS tool to develop the resource. For example, if one topic needs explanation using pictorial representation, then GIMP can be used, which is a free and open source image editing tool. Some of these tools are described below.

\subsubsection{Blender}

Blender is $3 D$ modelling and animation software, which is free and open source tool. Blender is used to create art, 3D models, and animated film. It can also be used for developing various educational materials such as animated lessons, games etc. This tool can be implemented on Windows, Macintosh as well as Linux environment. For example, in order to explain a concept related to a hardware device in a mechanical module, one can develop a 3D simulation of the same for better understanding during theory session.

\subsubsection{Qedoc Quiz Maker}

Qedoc Quiz Maker is a free and open source tool that is designed to create and modify the interactive learning. This software was developed by the IMAGE information system. With a very basic hardware requirement, this tool can be used with a very basic knowledge of computers. For example, faculty members can develop a simple quiz for revision, which they can provide to the students at the end of their session, in order to access the learning. Similarly, same quiz can be used at the beginning of next session, as brainstorming exercise.

\subsubsection{Pencil2D}

Pencil2D is a free and open source tool that is designed to make animation and drawing, by the traditional hand drew animation and by using the bitmap and vector graphic. This tool can be run on different platforms such as; Mac OS X, Windows, and Linux. This software can be useful to education proposes especially for 
first level learning. For example, modules such as physics, where any process need clear explanation, faculty can develop a simple animated demo using this tool. This way of visual learning could enhance the learning in the classroom.

\subsubsection{Alice}

Alice was born as a prototyping application. It is publishing virtual reality (VR) experiences which were aimed to be accessible to people who are not programmers. Alice is designed for teachers from middle schools to the universities level. People can deal with Alice inside and outside the classrooms. For example, for complex solutions related to computer networks, prototypes can be developed for better understanding and to perform various types of feasibility tests before the actual implementation which involves considerable amount of budget. Another interesting and effective area of implementation is Civil and Mechanical engineering, where VR experience can enhance the feasibility study process.

The above mentioned four tools provide just a glimpse of possibilities. On exploring further, there are several other tools such as Kdenlive and Openshot, which are non-linear video editing software. Xournal, a quick annotation tool for smart devices and Synfig Studio, a simple vector based 2D animation tool, are another example.

\subsection{Design of learning resources}

After identifying an appropriate tool for particular course content, learning resource development starts here. Sometimes, the OSS tool is new to use, and thus it needs a reference of some tutorials or helps files. This is the only time-consuming stage since the learning resources are built at this stage.

\subsection{Learning Management System - LMS}

Once the resources are ready, they are ready to share using LMS, such as Moodle. These resources are generally stored in the repository of the institution for later use, as well. LMS also allows faculty members to assess the learning by means of class assessments, such as online quiz, forum discussions etc.

\subsection{Implementation in class}

Finally, the resources and content are shared and the e-learning solution is implemented in the classes. It is suggested to have an active classroom environment for such implementation, where the faculty allows students to interact and explore more possibilities. Many kinds of research have shown a very positive result when e-learning resources are shared in a Student-Centric classroom environment that implements blended learning approach.

\subsection{Assessments, feedback and reflections}

To measure the effectiveness of this model, it is important to device appropriate assessment that measures the learning among the students. These assessments must be designed in such a way that student can reflect every learning outcome of the module. Feedback and reflections of above practices are other important measures to make sure the method is effective.

The first stage implementation of this method was done by producing some video tutorials of multimedia modules. These videos were edited using open source software. Later these were made available to the students on Moodle. As shown in Figure 2, more than $80 \%$ students found these materials useful.

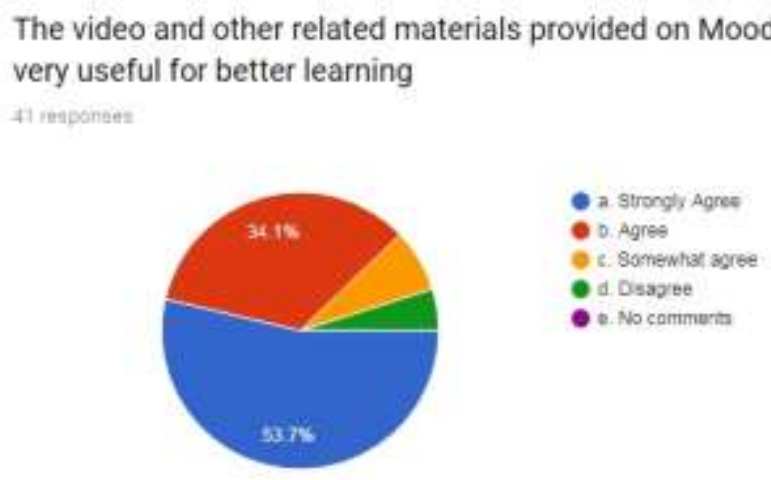

Figure 2. Feedback on usefulness 
For better understanding, senior students and peer tutors were encouraged to prepare these learning resources in native language, Arabic.

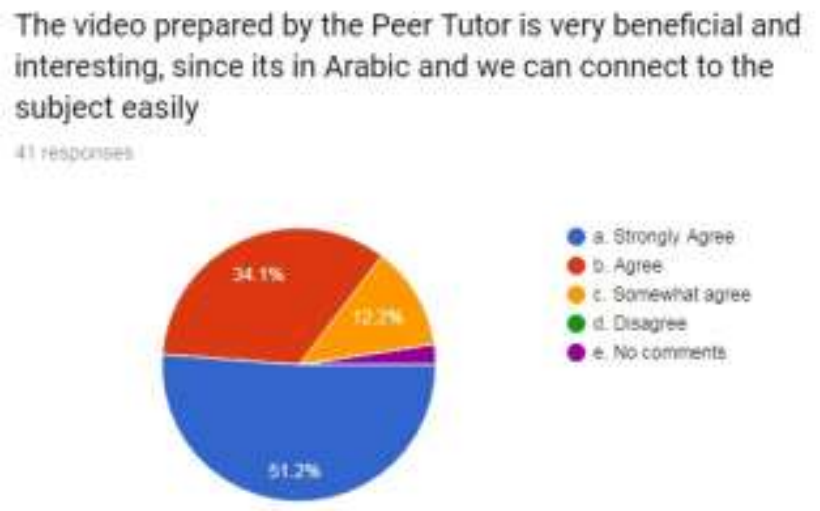

Figure 2. Feedback on LR prepared by peer tutor

It is very clear from figure 2 , that about $85 \%$ of the students are in favor of using learning resources prepared by senior students and peer tutors.

Based on the feedback and reflections, the developer/faculty further improves the learning resources for the next batch of students. And hence, the cycle of this methodology continues.

\section{CHALLENGES}

There are some major challenges in while implementing FOSS in higher education. One of them is capacitybuilding. Not every faculty member can develop new resources with an ease since open source software needs some basic knowledge of resource development. Another challenge faced by an educator is selflearning skills. This is because most of the OSS tools need self-learning and it is hard to find any institution that provides training on these tools. Therefore, most of the faculty members/developers depend on online shared learning resources, such as e-books, video tutorials, forum discussions etc.

\section{CONCLUSION}

FOSS tools are very effective especially in higher education since the current students are technically equipped with smart technology. They are ready to accept fun-based-learning environment and hence the traditional method of teaching and learning process should be used only when it is highly required, based on the topic or subject. The resource built at college or university level becomes an asset for that organization which can be further shared with affiliation attached to it. And thus, it can be good for marketing of the organization. Not only this but also, FOSS implementation develops entrepreneurship skills among educators and students, who can share their learning resources on some platforms which can generate revenue for the developers based on references and usage.

\section{ACKNOWLEDGEMENT}

Authors would like to acknowledge the management of Middle East College, Oman, for constantly providing support and encouragement towards research and innovation in academic practices. Thanks to Centre for Academic Practices, MEC, for providing regular staff development initiatives at the campus by means of the regular seminar, lectures, and workshops. They also extend their sincere acknowledgement to all the colleagues and friends who have encouraged them at every stage of this research.

\section{REFERENCE LIST}

A. Brocco and F. Frapolli, Open Source in Higher Education: Case Study Computer Science at the University of Fribourg, 1st ed. University of Fribourg, 2017, pp. 13-20.

"About - Alice", Alice.org, 2017. [Online]. Available: http://www.alice.org/about/. [Accessed: 08- Jun- 2017].

B. Foundation, "Blender Foundation — blender.org", blender.org, 2017. [Online]. Available: https://www.blender.org/foundation/. [Accessed: 08- Jun- 2017]. 
C. Zymaris, A catalogue of open source computer programs for teaching and learning, 1st ed. The National Center for Open Source and Education, 2017, pp. 25-29.

D. Lipsa and R. Laramee, "Open Source Software in Computer Science and IT Higher Education: A Case Study", cs.swan, 2017. [Online]. Available: http://cs.swan.ac.uk/ csbob/research/openSource/lipsa11open.pdf. [Accessed: 01- Jun- 2017].

I. Fuchs, challenges and opportunities of open sources in higher education, 1st ed. www.educause.edu, 2017, pp. 151-157.

M. Terbuc, "Use of Free/Open Source Software in e-education", researchgate, 2017. [Online]. Available: https://www.researchgate.net/publication/224382895_Use_of_FreeOpen_Source_Software_in_eeducation. [Accessed: 01- Jun- 2017].

P. Courant and R. Griffiths, Software and Collaboration in Higher Education: A Study of Open Source Software, 1st ed. sr.ithaka.org, 2017, pp. 13-24.

"Pencil2D - opensource animation software", Pencil2D - opensource animation software, 2017. [Online]. Available: http://www.pencil2d.org/. [Accessed: 08- Jun- 2017].

"Proprietary software versus Open Source Software for Education", www.ajer.org, 2013. [Online]. Available: http://www.ajer.org/papers/v2(7)/O027124130.pdf. [Accessed: 01- Jun- 2017].

Q. Maker and I. Ltd., "Qedoc Quiz Maker. Get the software safe and easy.", Software Informer, 2017. [Online]. Available: http://downloads.informer.com/qedoc-quiz-maker/. [Accessed: 08- Jun- 2017]. 